\title{
Research Paper: Comparison of Agonist vs. Antagonist Stimulation on Triceps Surae Spasticity in Spinal Cord Injury
}

\author{
Sneha Khanna ${ }^{1}$, Jaskirat Kaur ${ }^{2 *}$ \\ 1. Department of Neuro-Physiotherapy, Pushpanjali Crosslay Hospital, Vaishali, India. \\ 2. Institute of Rehabilitation Sciences, Vasant Kunj, Delhi, India.
}

Citation: Khanna S, Kaur J. Comparison of Agonist vs. Antagonist Stimulation on Triceps Surae Spasticity in Spinal Cord Injury. Iranian Rehabilitation Journal. 2017; 15(2):117-124. https://doi.org/10.18869/nrip.irj.15.2.117

Article info:

Received: 06 Dec. 2016

Accepted: 22 Mar. 2017

\section{Keywords:}

Agonist, Antagonist, Spasticity, Spinal cord injury, Modified ashworth scale

\section{ABSTRACT}

Objectives: One of the most common and disabling complications that affects individuals with spinal cord injury is spasticity. The purpose of this study is to compare the effect of agonist and antagonist electrical stimulations on triceps surae muscle spasticity in patients with spinal cord injury.

Methods: A total of 30 subjects with spinal cord injury were considered for the study. They were divided into two groups randomly. Group 1 received agonist electrical stimulation (stimulation of triceps surae) and group 2 received antagonist electrical stimulation (stimulation of tibialis anterior) for $20 \mathrm{~min}$, once daily, and 5 days per week for two weeks. To evaluate the therapeutic effect, modified Ashworth score, deep tendon reflex score and clonus score were tested before and after the treatment. Post treatment evaluation was made $24 \mathrm{~h}$ after the last treatment session.

Results: Both the groups showed significant reductions in the modified Ashworth scores and deep tendon reflex scores after the intervention, but these reductions were not found in the clonus score. Also, there was no significant difference in the post intervention scores of modified Ashworth scale, deep tendon reflex and clonus score between the two groups.

Discussion: This study provides evidence that both agonist electrical stimulation and antagonist electrical stimulations are equally effective in reducing spasticity in triceps surae muscle in patients with spinal cord injury.

\section{Introduction}

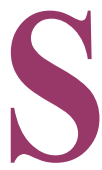

pasticity is one of the most common and potentially disabling complications that affect individuals with Spinal Cord Injury (SCI) $[1,2]$. The frequency of spasticity is $65 \%-78 \%$ in individuals with traumatic
SCI $[3,4]$. Mild spasticity may have benefits such as maintenance of muscle tone and circulation of blood in the muscles; however, it is associated with secondary negative consequences like pain, fatigue and contractures $[5,6]$. Spasticity has been reported to significantly impact activities of daily living, impede rehabilitation ef-

* Corresponding Author:

Jaskirat Kaur, PhD

Address: Institute of Rehabilitation Sciences, Vasant Kunj, Delhi, India.

Tel: +91 (98) 91264977

E-mail: drjaskirat24@gmail.com 
forts, limit workplace participation, as well as add to the cost of medications and attendant care $[3,6]$.

Spasticity is a motor disorder characterized by hypertonia, hyperreflexia, clonus, and painful muscle spasms occurring in response to stretch or noxious cutaneous stimulation [7]. Others have proposed new definitions reflecting the multidimensional nature of spasticity, such as 'disordered sensorimotor control, resulting from an upper motor neuron lesion, presenting as intermittent or sustained involuntary inactivation of muscle' [8] or 'characterization of spasticity comprising of intrinsic tonic, intrinsic phasic and extrinsic components' [7]. Many treatment modalities are available for reducing spasticity. Some of these modalities include oral medications $[6,9,10]$, chemodenervation and neurolysis [6], implanted pumps [11], physical therapy [6], epidural spinal cord stimulation [12], and surgery [6]. It is generally agreed that physical therapy is an essential component in the management of spasticity.

In addition, therapeutic electrical stimulation is also known to reduce spasticity. Several studies have shown the efficacy of electrical stimulation on spasticity in patients with SCI [13-16]. However, there are various methods of electrical stimulation for spasticity reduction. Some studies described stimulation of the spastic muscle itself, i.e., the agonist muscle [14, 15, 17-19], whereas some other studies have resorted to stimulation of the antagonistic muscle [20-22]. Stimulation of the spastic muscle is based on recurrent inhibition. This is thought to be caused by the Renshaw cell, which has a negative feedback loop to the alpha motor neuron, and this mechanism is found to be decreased in spastic patients [23]. Agonist muscle stimulation can be used to enhance the recurrent inhibition as an inhibitory pathway for the agonist muscle [16]. Antagonist muscle stimulation enhances the mechanism of reciprocal inhibition, which is seen to be decreased in patients with SCI [24].

It may aid in enhancing the mechanism of reciprocal inhibition, which may be beneficial in reducing spasticity [16]. However, there is limited evidence available on the optimal methods of stimulation. Only one study has compared the effects of three different methods of electrical stimulation in reducing spasticity. In this study, the patient was given stimulation for only one session, and on each day, a different intervention was applied as follows: agonist stimulation, antagonist stimulation, dermatome stimulation or a placebo approach. The purpose of this study was to compare the effect of two weeks of agonist stimulation (electrical stimulation of triceps surae) and antagonist stimulation (electrical stimulation of tibialis anterior) on the spasticity of triceps surae muscle in patients with SCI.

\section{Methods}

Thirty SCI patients were recruited from the Indian Spinal Injury Centre, Delhi for this study. To participate, the subjects had to meet the following criteria: Subjects with traumatic SCI ASIA impairment grade A, B, C and $\mathrm{D}$; age between 18-55 years; spasticity in triceps surae muscle with spasticity grade of equal to or greater than 1 and less than or equal to 3 on the modified Ashworth scale; time since injury should be at least 6 months; and no change in the anti-spasticity medication within two weeks before and during the study period [16, 19, 22]. Subjects with ankle contracture or deformity; subjects with spasticity due to any other neurologic condition, except traumatic SCI; presence of open wounds and absolute contraindications to electrical stimulation like the presence of metal implants in the affected leg, tumor, infections, etc. were excluded from the study. The study was approved by the Institutional Review Board, and all ethical principles concerning the use of human volunteers were followed during this research.

Subjects were invited to participate in the study and were randomly divided into two groups. A detailed explanation of the procedure was given to the patients after which they signed the informed consent. Subjects in group 1 received agonist electrical stimulation and those in group 2 received antagonist electrical stimulation. Spasticity in triceps surae muscle was measured by noting the modified Ashworth score, deep tendon reflex grade and clonus score by two raters three times (out of which mode was taken) before and after the intervention. Post-intervention assessment was done $24 \mathrm{~h}$ after the last treatment session. Rater 1 was blinded to the method of stimulation. Both the raters were qualified physiotherapists.

The testing area was quiet and screened from other patients and therapists. Data was recorded from the data collection form along with the other details of the patient. For the analysis purpose, only the data obtained from the right ankle was noted. All the subjects in both the groups received the intervention for $20 \mathrm{~min}, 5$ times per week for two weeks. The intervention was given early in the morning before the patient started with the conventional exercise routine, which consisted of passive cycling, standing on tilt table or standing frame, passive and active exercises and training of Activities of Daily Living (ADL). Subjects were shifted onto a padded couch and made to lie supine with a pillow under the knee of the leg to be stimulated to relax the triceps 
surae muscle. Skin was cleaned before the application of electrodes. Stimulation was applied through carbon rubber electrodes [25].

For the muscle stimulation, the electrodes were applied on triceps surae muscle in subjects of agonist group, and on tibialis anterior in the subjects of antagonist group. The electrodes were applied on the respective muscle belly just proximal to and distal to the motor point of the muscle [26]. Between the electrodes and the skin, a conductive gel was applied. The electrodes were then strapped to the limb with velcro straps. Stimulation parameters were set on the equipment and then the intensity was gradually increased to elicit palpable muscle contraction. Both the groups had the same stimulation parameters as follows: Pulse width: 300 ms; Pulse rate: 30 Hz; Burst duration: 4 s; Ramp up time: $1 \mathrm{~s}$; and Pause duration: $4 \mathrm{~s}$.

\section{Intensity}

It was the minimum intensity that produced palpable muscle contraction. If this intensity evoked spasms, then stimulation amplitude was set just below the level at which spasms occurred.

After stimulation, the electrodes were removed, and the gel was cleaned with cotton swab. The subjects received electric stimulation for $20 \mathrm{~min}, 5$ days per week for two weeks [26]. Post intervention evaluation was made $24 \mathrm{~h}$ after the last treatment session.

\section{Statistics}

Statistics was performed using SPSS software version 17. A Mann-Whitney's test was used to analyze the difference between the two groups on scores of modified Ashworth scale, deep tendon reflex grading scale, and clonus grading scale. Intra-group analysis between pre-intervention scores and post-intervention scores of modified Ashworth scale, deep tendon grading scale and clonus grading scale was done using Wilcoxon's signed rank test. Inter-rater agreement was analyzed using kappa statistic. A significance level of $\mathrm{P} \leq 0.05$ was fixed.

\section{Results}

The two groups (Table 1) were analyzed with res modified Ashworth scale (Table 2, 3, 4). Post intervention scores between Group 1 and Group 2 was done on modified Ashworth scale, deep tendon reflexes grading scale, clonus grading scale (Figure 1). Inter-rater agreement was also analyzed. For the numerical analysis of modified Ashworth scale, the 1+value was ascribed as 2, thus value 2 was ascribed as 3, and so on. Readings by rater 1 were analyzed as rater 1 was blinded to the method of stimulation. The inter-rater agreement for pre-intervention score on modified Ashworth scale was moderate $(\mathrm{k}=0.54$, $\mathrm{P}>0.001)$. The agreements for pre-intervention score on deep tendon reflex and on clonus were almost perfect $((\mathrm{k}=0.91, \mathrm{P}>0.001)$ and $(\mathrm{k}=0.90, \mathrm{P}>0.001)$, respectively $)$.

\section{Discussion}

A battery of tests was used for the assessment of spasticity in this study to increase the reliability of the outcome. Besides modified Ashworth scale, deep tendon reflex and clonus were also included as they provided extra information on the phasic component of the stretch reflex, which is not addressed by the modified Ashworth scale. The literature shows that modified Ashworth scale has a limited inter-rater reliability for measuring lower limb spasticity $[7,8]$. In order to increase the reliability of outcome measures, two raters noted the readings in this study, and the inter-rater agreement was analyzed. Rater 1 was blinded to the method of stimulation, and hence, the readings by rater 1 were taken into consideration for data analysis. Inter-rater agreement was found to be moderate for scores on modified Ashworth scale $(\mathrm{k}=0.54, \mathrm{P}>0.001)$ and almost perfect for deep tendon reflex $(\mathrm{k}=0.91, \mathrm{P}>0.001)$ and clonus $(\mathrm{k}=0.90, \mathrm{P}>0.001)$.

In this study, electrical stimulation was given in resting position of the ankle joint. In Vodovnik et al's [13] study, the movements of limbs were allowed to occur with electrical stimulation. However, movement of the stimulated limbs in itself may have caused the effect found in these studies because limb movement produces muscle stretch, which is a commonly applied and effective method for treating spasticity. None of the subjects in our study reported adverse effects or increased spasms due to the interventions.

On comparing the pre intervention scores and post intervention scores of group 1, it was found that there was a significant improvement in modified Ashworth score $(\mathrm{z}=3.13, \mathrm{P}>0.002)$ and deep tendon reflex score $(\mathrm{z}=2.65$, $\mathrm{P}>0.008$ ). However, no significant difference was seen in the clonus scores. These findings were in accordance with the previous studies of Aydin et al., [17] and Bryan Ping et al., [19] who also demonstrated a decrease in the modified Ashworth scores and Achilles tendon reflex with transcutaneous electrical nerve stimulation. Studies by Lee et al., [27], Chen SC et al., [18] and Robinson et al., $[14,15]$ have also shown spasticity to decrease with surface electrical stimulation of spastic muscle. Physio- 
Table 1. Demographic characteristics of group 1 and group 2

\begin{tabular}{|c|c|c|c|}
\hline Variables & $\begin{array}{c}\text { Group } 1(n=15) \\
\text { Mean } \pm S D\end{array}$ & $\begin{array}{c}\text { Group } 2(n=15) \\
\text { Mean } \pm S D\end{array}$ & $\mathbf{T}$ \\
\hline Age & $31.33 \pm 8.24$ & $28.53 \pm 8.55$ & $0.91^{\mathrm{N} . \mathrm{S}}$ \\
\hline Gender & $M-11, F-4$ & M-10, F-5 & \\
\hline AIS grade & $\begin{array}{c}\text { AIS A-10, } \\
\text { AIS B-4 } \\
\text { AIS C-1 }\end{array}$ & $\begin{array}{l}\text { AIS A-11 } \\
\text { AIS B-4 }\end{array}$ & \\
\hline Time since injury & $15.13 \pm 6.06$ & $15.07 \pm 6.30$ & $0.03^{\mathrm{N} . \mathrm{S}}$ \\
\hline Pre intervention MAS & $3.27 \pm 0.80$ & $3.25 \pm 0.86$ & $0.18^{\mathrm{N} . \mathrm{S}}$ \\
\hline Pre intervention deep tendon reflex & $3.20 \pm 0.46$ & $3.15 \pm 0.41$ & $0.42^{\mathrm{N} . \mathrm{S}}$ \\
\hline Pre intervention clonus & $1.87 \pm 0.83$ & $2.2 \pm 0.68$ & $1.10^{\mathrm{N} . \mathrm{S}}$ \\
\hline
\end{tabular}

N.S: Not Significant; AIS: Asia Impairment Scale; Group 1: Agonist stimulation group;

Iranian Rehabilitation Journal

Group 2: Antagonist stimulation group; MAS: Modified Ashworth Scale

Table 2. Comparison of pre-intervention scores and post-intervention scores of modified Ashworth scale, deep tendon reflex and clonus in group 1 and group 2

\begin{tabular}{|c|c|c|c|c|c|c|}
\hline \multirow[b]{2}{*}{ Variable } & \multicolumn{2}{|c|}{ Group 1 (n=15) } & \multirow[b]{2}{*}{$\mathbf{z}$} & \multicolumn{2}{|c|}{ Group 2 (n=15) } & \multirow[b]{2}{*}{$\mathbf{Z}$} \\
\hline & $\begin{array}{l}\text { Pre-Interven- } \\
\text { tion Scores } \\
\text { Mean士SD }\end{array}$ & $\begin{array}{l}\text { Post-Interven- } \\
\text { tion Scores } \\
\text { Mean士SD }\end{array}$ & & $\begin{array}{c}\text { Pre-intervention } \\
\text { Scores } \\
\text { Mean } \pm S D\end{array}$ & $\begin{array}{l}\text { Post-interven- } \\
\text { tion Scores } \\
\text { Mean士SD }\end{array}$ & \\
\hline MAS & $3.27 \pm 0.80$ & $2.53 \pm 0.64$ & $3.13^{*}$ & $3.25 \pm 0.86$ & $2.67 \pm 0.82$ & $2.83^{*}$ \\
\hline Deep tendon reflex & $3.20 \pm 0.46$ & $2.80 \pm 0.41$ & $2.65^{*}$ & $3.15 \pm 0.41$ & $2.93 \pm 0.46$ & $2.00^{*}$ \\
\hline Clonus & $1.87 \pm 0.83$ & $1.73 \pm 0.88$ & $1.41^{\mathrm{N} . S}$ & $2.2 \pm 0.68$ & $2.20 \pm 0.18$ & $1.98^{\mathrm{N} . S}$ \\
\hline
\end{tabular}

N.S: Not Significant; *: Significant at P $\leq 0.05$; MAS: Modified Ashworth Scale

Iranian Rehabilitation Journal

logically, this can be explained by enhanced recurrent inhibition, which is thought to be caused by Renshaw cell.

Group 2 also showed a significant difference in pre intervention and post intervention scores of modified Ashworth score $(\mathrm{z}=2.83, \mathrm{P}>0.005)$ and deep tendon reflex $(\mathrm{z}=2.0, \mathrm{P}>0.045)$, but no difference was seen in the clonus score. In their study, Alfieri et al., [20] re- ported that spasticity in wrist and finger flexors tended to decrease after stimulation of the antagonistic muscle group. Levine and group [21] have also shown a decrease in hamstring spasticity with surface electrical stimulation of the quadriceps and iliopsoas. Seib et al., [22] have shown decreased spasticity in gastrocnemius after stimulation of tibialis anterior muscle. In theory, the therapeutic mechanism by which antagonist stimulation

Table 3. Comparison of post-intervention scores of modified Ashworth scale, deep tendon reflex and clonus between two groups

\begin{tabular}{|c|c|c|c|c|c|}
\hline \multirow{2}{*}{ Variable } & \multicolumn{2}{|c|}{$\begin{array}{c}\text { Post-Intervention Scores } \\
\text { Group } 1(n=15)\end{array}$} & \multicolumn{2}{|c|}{$\begin{array}{l}\text { Post-Intervention Scores } \\
\text { Group } 2(n=15)\end{array}$} & \multirow[t]{2}{*}{$\mathbf{Z}$} \\
\hline & Mean & SD & Mean & SD & \\
\hline MAS & 2.53 & 0.64 & 2.67 & 0.82 & $0.61^{\text {N.S }}$ \\
\hline Deep tendon reflex & 2.8 & 0.41 & 2.93 & 0.46 & $0.81^{\text {N.S }}$ \\
\hline Clonus & 1.73 & 0.88 & 2.20 & 0.68 & $1.51^{\text {N.S }}$ \\
\hline
\end{tabular}

N.S: Not Significant; Group 1: Agonist stimulation group;

Group 2: Antagonist stimulation group; MAS: Modified Ashworth Scale 
Table 4. Inter rater agreement of scores of Modified Ashworth scale, deep tendon reflex and clonus between rater one and rater two

\begin{tabular}{ccc}
\hline & $\mathbf{N}=\mathbf{3 0}$ & \\
\hline Variable & Agreement (\%) & Kappa Value \\
\hline Modified Ashworth scale & 70 & $0.54^{*}$ \\
Deep tendon reflex & 96.67 & $0.91^{*}$ \\
\hline Clonus & 93.33 & $0.90^{*}$ \\
\hline
\end{tabular}

*: Significant at $P \leq 0.05$

Iranian Rehabilitation Journa

decreases spasticity is based on reciprocal inhibition and relaxation of the muscle by Golgi organ activation of the spastic muscle.

There was a significant reduction in the post-intervention modified Ashworth scores of both the groups. However, because MAS measures both the spastic hypertonia and the mechanical components of muscle stiffness, it is not clear which component has primarily changed. On comparison of the post-intervention scores, no significant difference was found in the modified Ashworth scores and deep tendon reflex scores of both the groups. In a similar study done by Arjan Van der Salm et al., [16] to compare the effect of three methods of electrical stimulation in triceps surae in a group of 10 SCI patients, a significant reduction in modified Ashworth scores was found with agonist stimulation in comparison to antagonist stimulation.

In addition, a significant reduction was seen at the angle at which reflex started, which was found with antagonist stimulation in comparison to agonist stimulation. However, their findings were based on a single session of electrical stimulation. In our study, 10 out of 15 patients showed reduced spasticity in the agonist stimulation group, and 8 out of 15 patients showed reduced spasticity in antagonist stimulation group. Moreover, different outcomes may be related to a wide variety of stimulation parameters, application methods and quantification measurements used.

While definitive conclusions cannot be drawn from this study as it lacked a control group and no objective measures were used, the results of this study can be compared favorably with the previous studies that have shown the efficacy of electrical stimulation in reducing spasticity. As an additional measure, we had also taken readings on SCI spasticity evaluation tool (SCI-SET) [28]. It is a 7-day recall self-report questionnaire that takes into account both the problematic and useful effects of spasticity in daily life of people with SCI. A majority of the patients reported less impact of spasticity in activities like transfers, turning in bed after two weeks of electrical stimulation. However, the scale was more relevant to

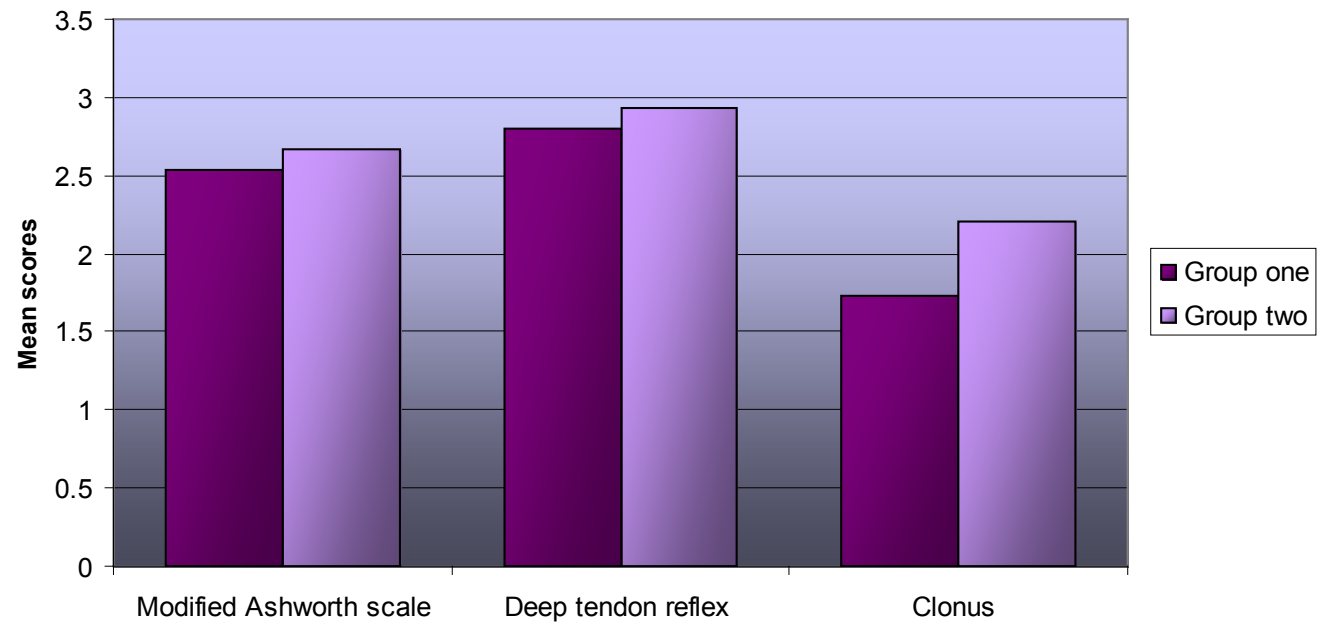

Comparison of post-intervention scores of modified Ashworth scale, deep tendon reflex and clonus between two groups

Figure 1. Comparison of post intervention scores of group 1 and group 2

Group 1: Agonist stimulation group; Group 2: Antagonist stimulation group 
measure the impact of interventions, which affected the whole body spasticity. Thus, the effect of agonist and antagonist stimulations in reducing the impact of spasticity in activities of daily living needs further investigation.

At the same time, although the effects were statistically significant for both the agonist and antagonist electrical stimulations that were found to be equally effective in reducing the modified Ashworth scores and deep tendon reflex scores in triceps surae muscle, there is still a need for more studies to know how long the effects last. The results of this study support the use of both agonist and antagonist electrical stimulations as an intervention to decrease spasticity in individuals with SCI. Future studies can be done to see the carry over effect of agonist and antagonist electrical stimulations given over a period of weeks. The study had certain limitations. The carryover of the effect of electrical stimulation on spasticity could not be studied. Other confounding variables that affect spasticity such as pain, constipation, fatigue, mental status, and temperature could not be controlled.

\section{Conclusion}

This study concludes that both agonist and antagonist electrical stimulations for two weeks were effective in reducing spasticity in triceps surae muscle in SCI patients. There was no significant difference in spasticity reduction produced by agonist and antagonist electrical stimulations.

\section{Acknowledgments}

This research did not receive any specific grant from funding agencies in the public, commercial, or not-forprofit sectors.

\section{Conflict of Interest}

All authors certify that this manuscript has neither been published in whole nor in part nor being considered for publication elsewhere. The authors have no conflicts of interest to declare.

\section{References}

[1] Levi R, Hultling C, Nash MS, Seiger Å. The Stockholm spinal cord injury study: 1 . Medical problems in a regional SCI population. Paraplegia. 1995; 33(6):308-15. doi: 10.1038/ sc. 1995.70
[2] Elbasiouny SM, Moroz D, Bakr MM, Mushahwar VK. Management of spasticity after spinal cord Injury: Current techniques and future directions. Neurorehabilitation and Neural Repair. 2010; 24(1), 23-33. doi: 10.1177/1545968309343213

[3] Sköld C, Levi R, Seiger Å. Spasticity after traumatic spinal cord injury: Nature, severity, and location. Archives of Physical Medicine and Rehabilitation. 1999; 80(12):1548-57. doi: 10.1016/s0003-9993(99)90329-5

[4] Maynard FM, Karunas RS, Waring WP. Epidemiology of spasticity following traumatic spinal cord injury. Archives of Physical Medicine and Rehabilitation. 1990; 71(8):566-9. PMID: 2369291

[5] Johnson RL, Gerhart KA, McCray J, Menconi JC, Whiteneck GG. Secondary conditions following spinal cord injury in a population-based sample. Spinal Cord. 1998; 36(1):45-50. doi: 10.1038/sj.sc.3100494

[6] Adams MM, Hicks AL. Spasticity after spinal cord injury. Spinal Cord. 2005; 43(10):577-86. doi: 10.1038/sj.sc.3101757

[7] Hsieh JTC, Wolfe DL, Miller WC, Curt A. Spasticity outcome measures in spinal cord injury: Psychometric properties and clinical utility. Spinal Cord. 2007; 46(2):86-95. doi: 10.1038/ sj.sc.3102125

[8] Pandyan A, Gregoric M, Barnes M, Wood D, Wijck FV, Burridge J, et al. Spasticity: Clinical perceptions, neurological realities and meaningful measurement. Disability and Rehabilitation. 2005; 27(1-2):2-6. doi: 10.1080/09638280400014576

[9] Gruenthal M, Mueller M, Olson WL, Priebe MM, Sherwood $\mathrm{AM}$, Olson WH. Gabapentin for the treatment of spasticity in patients with spinal cord injury. Spinal Cord. 1997; 35(10):686-9. doi: 10.1038/sj.sc.3100481

[10] Norman KE, Pépin A, Barbeau H. Effects of drugs on walking after spinal cord injury. Spinal Cord. 1998; 36(10):699-715 doi: $10.1038 /$ sj.sc.3100674

[11] Guglielmino A, Sorbello M, Fazzio S, Zingale SF, Bucolo GE, Pittalà G, et al. Continuous intrathecal baclofen administration by a fully implantable electronic pump for severe spasticity treatment: Our experience. Minerva Anestesiologica. 2006; 72(10):807-20. PMID: 17006418

[12] Pinter MM, Gerstenbrand F, Dimitrijevic MR. Epidura electrical stimulation of posterior structures of the human lumbosacral cord: 3. Control of spasticity. Spinal Cord. 1999; 38(9):524-31. doi: 10.1038/sj.sc.3101040

[13] Vodovnik L, Bowman BR, Hufford P. Effects of electrical stimulation on spinal spasticity. Scandinavian Journal of Rehabilitation Medicine. 1984; 16(1):29-34. PMID: 6608787

[14] Robinson CJ, Kett NA, Bolam JM. Spasticity in spinal cord injured patients: Short-term effects of surface electrical stimulation. Archives of Physical Medicine and Rehabilitation. 1988; 69(8):598-604. PMID: 3261577

[15] Robinson CJ, Kett NA, Bolam JM. Spasticity in spinal cord injured patients: Initial measures and long-term effects of surface electrical stimulation. Archives of Physical Medicine and Rehabilitation. 1988; 69(10):862-8. PMID: 3263102

[16] Van der Salm A, Veltink PH, IJzerman MJ, Groothuis-Oudshoorn KC, Nene AV, Hermens HJ. Comparison of electric stimulation methods for reduction of triceps surae spasticity 
in spinal cord injury. Archives of Physical Medicine and Rehabilitation. 2006; 87(2):222-8. doi: 10.1016/j.apmr.2005.09.024

[17] Aydn G, Tomruk S, Kele I, Demir SZ, Orkun S. Transcutaneous electrical nerve stimulation versus baclofen in spasticity: Clinical and electrophysiologic comparison. American Journal of Physical Medicine \& Rehabilitation. 2005; 84(8):584-92. doi: 10.1097/01.phm.0000171173.86312.69

[18] Chen SC, Chen YL, Chen CJ, Lai CH, Chiang WH, Chen WL. Effects of surface electrical stimulation on the muscle-tendon junction of spastic gastrocnemius in stroke patients. Disability and Rehabilitation. 2005; 27(3):105-10. doi: 10.1080/09638280400009022

[19] Ping Ho Chung B, Kam Kwan Cheng B. Immediate effect of transcutaneous electrical nerve stimulation on spasticity in patients with spinal cord injury. Clinical Rehabilitation. 2010; 24(3):202-10. doi: 10.1177/0269215509343235

[20] Alfieri V. Electrical treatment of spasticity: Reflex tonic activity in hemiplegic patients and selected specific electrostimulation. Scandinavian Journal of Rehabilitation Medicine. 1982; 14(4):177-82. PMID: 6983718

[21] Levine MG, Knott M, Kabat H. Relaxation of spasticity by electrical stimulation of antagonist muscles. Archives of Physical Medicine and Rehabilitation. 1952; 33(11):668-673. PMID: 12997297

[22] Seib TP, Price R, Reyes MR, Lehmann JF. The quantitative measurement of spasticity: Effect of cutaneous electrical stimulation. Archives of Physical Medicine and Rehabilitation. 1994; 75(7):746-50. PMID: 8024418

[23] Mazzocchio R. Involvement of spinal recurrent inhibition in spasticity. Further insight into the regulation of Renshaw cell activity. Brain. 1997; 120(6):991-1003. doi: 10.1093/ brain/120.6.991

[24] Xia R, Rymer WZ. Reflex reciprocal facilitation of antagonist muscles in spinal cord injury. Spinal Cord. 2004; 43(1):1421. doi: $10.1038 /$ sj.sc.3101656

[25] Tuszynski MH, Steeves JD, Fawcett JW, Lammertse D, Kalichman M, Rask C, et al. Guidelines for the conduct of clinical trials for spinal cord injury as developed by the ICCP Panel: Clinical trial inclusion/exclusion criteria and ethics. Spinal Cord. 2006; 45(3):222-31. doi: 10.1038/sj.sc.3102009

[26] Santos M, Zahner LH, McKiernan BJ, Mahnken JD, Quaney B. Neuromuscular electrical stimulation improves severe hand dysfunction for individuals with chronic stroke. Journal of Neurologic Physical Therapy. 2006; 30(4):175-83. doi: 10.1097/01.npt.0000281254.33045.e4

[27] Lee WJ, McGovern JP, Duval EN. Continuous tetanizing (low voltage) currents for relief of spasm. Occupational Therapy \& Rehabilitation. 1951; 30(5):313

[28] Adams MM, Martin Ginis KA, Hicks AL. The spinal cord injury spasticity evaluation tool: Development and evaluation. Archives of Physical Medicine and Rehabilitation. 2007; 88(9):1185-92. doi: 10.1016/j.apmr.2007.06.012 
